\title{
On the Embryology of Two Species of Genus Lepidium (Brassicaceae)
}

\author{
Elina Yankova-Tsvetkova \\ Department of Plant and Fungal Diversity and Resources, Institute of \\ Biodiversity and Ecosystem Research, Bulgarian Academy of Sciences, \\ Sofia 1113, Bulgaria
}

Ivanka B. Semerdjieva

Department of Botany and Agrometeorology, Faculty of Agronomy, Agricultural University, Plovdiv 4000, Bulgaria

\section{Rozalia Nikolova}

Department of Plant and Fungal Diversity and Resources, Institute of Biodiversity and Ecosystem Research, Bulgarian Academy of Sciences, Sofia 1113, Bulgaria

\section{Valtcho D. Zheljazkov ${ }^{1}$ \\ Department of Crop and Soil Science, Oregon State University, Corvallis, OR 97331}

Additional index words. Lepidium campestre, Lepidium ruderale, embryo and endosperm formation, male and female gametophyte

\begin{abstract}
Some species of genus Lepidium of the family Brassicaceae are ruderal plants, and they can grow well on less fertile soils and may have potential as oilseed crops for marginal lands. To develop cultivation techniques for wild species, the reproductive capacity of the species needs to be revealed. The objective of this work was embryological study of two Lepidium species (L. campestre and $L$. ruderale). As a result of the study, the main features of male and female generative spheres were established. Male generative sphere: The anther is tetrasporangiate and its wall, the development of which follows the monocotyledonous-type, consists of epidermis, endothecium, one middle layer, and glandular tapetum. Predominantly, tetrahedral microspore tetrads form after simultaneous type of microsporogenesis. The mature pollen grains are two-celled. Female generative sphere: The mature ovule is ana-amphytropous, crassinucellate, and bitegmic with unicellular archesporium that functions as a megaspore mother cell without cutting off of parietal cells. The development of the embryo sac follows the polygonum-type development. The embryo and endosperm develop after the onagrad-type embryogenesis. The established peculiarities of the reproductive biology characterize the studied species as sexually reproducing taxa that guarantee the stability of size of their populations. This is important for the conservation of these species as part of the Bulgarian flora biodiversity given their status of valuable medicinal plants. The data obtained will contribute to the knowledge of the embryological characteristic of genus Lepidium. The results contribute to the understanding of Lepidium biology and potential development of Lepidium species as oilseed cash crops for marginal lands.
\end{abstract}

The increase in world population and the development of various industries requiring natural raw products are prerequisite for increased production and use of oilseed crops. Major oilseed crops are economically and ecologically important and are grown, as cash crops, on fertile and well-aerated land. However, it is increasingly difficult to increase cultivated areas because of the scarcity of arable land (Ivarson, 2016). This scarcity of

Received for publication 7 Dec. 2017. Accepted for publication 23 Jan. 2018

This research was partially supported by start-up funding from Oregon State University awarded to Zheljazkov (Jeliazkov).

${ }^{1}$ Corresponding author. E-mail: valtcho.jeliazkov@ oregonstate.edu or valtcho.pubs@gmail.com. arable lands calls for the search of alternative oilseed crops that could be produced on marginal lands. Some species of genus Lepidium of the family Brassicaceae are ruderal plants and produce seeds rich in fatty acid oils (Eriksson and Merker, 2011; Merker et al., 2010). The genus Lepidium L. (Brassicaceae), includes about 220 species, distributed in the Americas, Africa, Asia, Europe, and Australia (Al-Shehbaz and Gaskin, 1993; Delipavlov et al., 2003). Some Lepidium species, such as L. sativum L. (garden cress) and L. meyenii Walp (maca), are grown as vegetables. In recent years, researchers focused on studies on biological activity, genetic potential for fat synthesis, and medical application of a number of Lepidium species (Chyad, 2017; Gan et al., 2017; Ivarson et al.,
2017; Kamani et al., 2017; Sánchez et al., 2017). Attempts are being made to cultivate L. campestre as oilseed crop. It has been shown that genetic modification of L. campestre could increase fatty acid oil yield by almost $30 \%$ (Ivarson et al., 2017). Merker et al. (2010) reported a relatively high seed yield of $(4.8 \mathrm{t} / \mathrm{ha})$ of $L$. campestre in rotational field study. Ivarson (2016) also reported that L. campestre had potential as an oilseed crop.

When developing the cultivation technology of a given species, it is important to know the species reproductive capacity, which is limited for $L$. campestre and $L$. ruderale. Therefore, this study focused on the embryological study on two Lepidium species from Bulgarian flora [L. campestre (L.) R. Br. and L. ruderale L.]. So far, there has been only fragmented data on the embryology of this genus (Belyaeva and Rodionova, 1983). The present study aimed to reveal the peculiarities of embryological structures and processes of $L$. campestre and $L$. ruderale, as well as the mode of their reproduction, to estimate the state of population of these species.

\section{Material and Methods}

Plant material. We used flower buds and flowers, at different developmental stages, collected from one population of $L$. campestre established at the Botanical Garden of Bulgarian Academy of Science in Sofia and one natural population of $L$. ruderale established in the outskirts of Sofia, Bulgaria.

Young and open capitula were collected and fixed in a mixture of FAA (5 parts formalin : 5 parts glacial acetic acid : 90 parts of $70 \%$ ethanol). The fixed plant material was dehydrated in ascending ethanol series, embedded in paraffin according to the classical paraffin methods (Sundara, 2000). Consequently, the embedded paraffin material was cut into $6-12 \mu \mathrm{m}$ sections with a rotary microtome. The sections were stained with Heidenhain's haematoxylin (Romeis, 1948) and embedded in Entellan, to develop permanent slides.

The main embryological structures and processes in the male and female generative sphere were established after observations using LM "Olympus" CX2 (Olympus Europa SE \& CoKG, Hamburg, Germany). The microphotographs were made using "Infinity lite" digital camera 1,4 Mpx (Lumenera Corporation, Ontario, Canada).

\section{Results and Discussion}

To our knowledge, this is the first study on the peculiarities of the reproductive structure and processes of the two Lepidium species. The observation of the prepared microscope slides showed that the structure and processes in the reproductive sphere in the two studied Lepidium species were similar and followed the embryological characteristics described as typical for other species that are members of the family Brassicaceae (Belyaeva and Rodionova, 
1983; Davis, 1966; Poddubnaja-Arnoldi, 1982; Watson and Dallwitz, 1992), as follows.

Anther and development of the male gametophyte. The anthers were tetrasporangiate. The anther wall develops after the monocotyledonous-type according to Davis' classification (Davis, 1966). It consisted of four layers: an epidermis, an endothecium, one middle layer, and a tapetum. At the beginning of anther's ontogenesis, the anther's wall layers were almost similar in shape and size (Fig. 1A) but after the formation of microspore tetrads they begun to distinguish (Fig. 1B). The epidermis comprised one row of almost rectangular onenucleate cells that vastly enlarged during the anther's ontogenesis. The middle layer consisted of one row of tangentially stretchened cells. The endothecium was one-rowed and its consisting cells were rectangular at the beginning of anther's ontogenesis, but subsequently they radially lengthen and developed fibrous thickenings (Fig. 1C and D). The one-layered tapetum was glandular during the whole anther ontogenesis. Initially, its consisting cells were one-nucleate but even at the stage of microspore mother cells (MMCs), they became two-nucleate (Fig. 1B) as a result of a mitotic division. At the stage of mature pollen, the anther wall consisted of one-rowed endothecium and epidermis, partially preserved middle layer and rests of tapetum (Fig. 1D).

The sporogenous tissue was multilayered (Fig. 1A) as in most representatives of the Brassicaceae family (Poddubnaja-Arnoldi, 1982). Initially, the sporogenous cells were polygonal and fitted closely to each other (Fig. 1A). Later on, they elongated, rounded
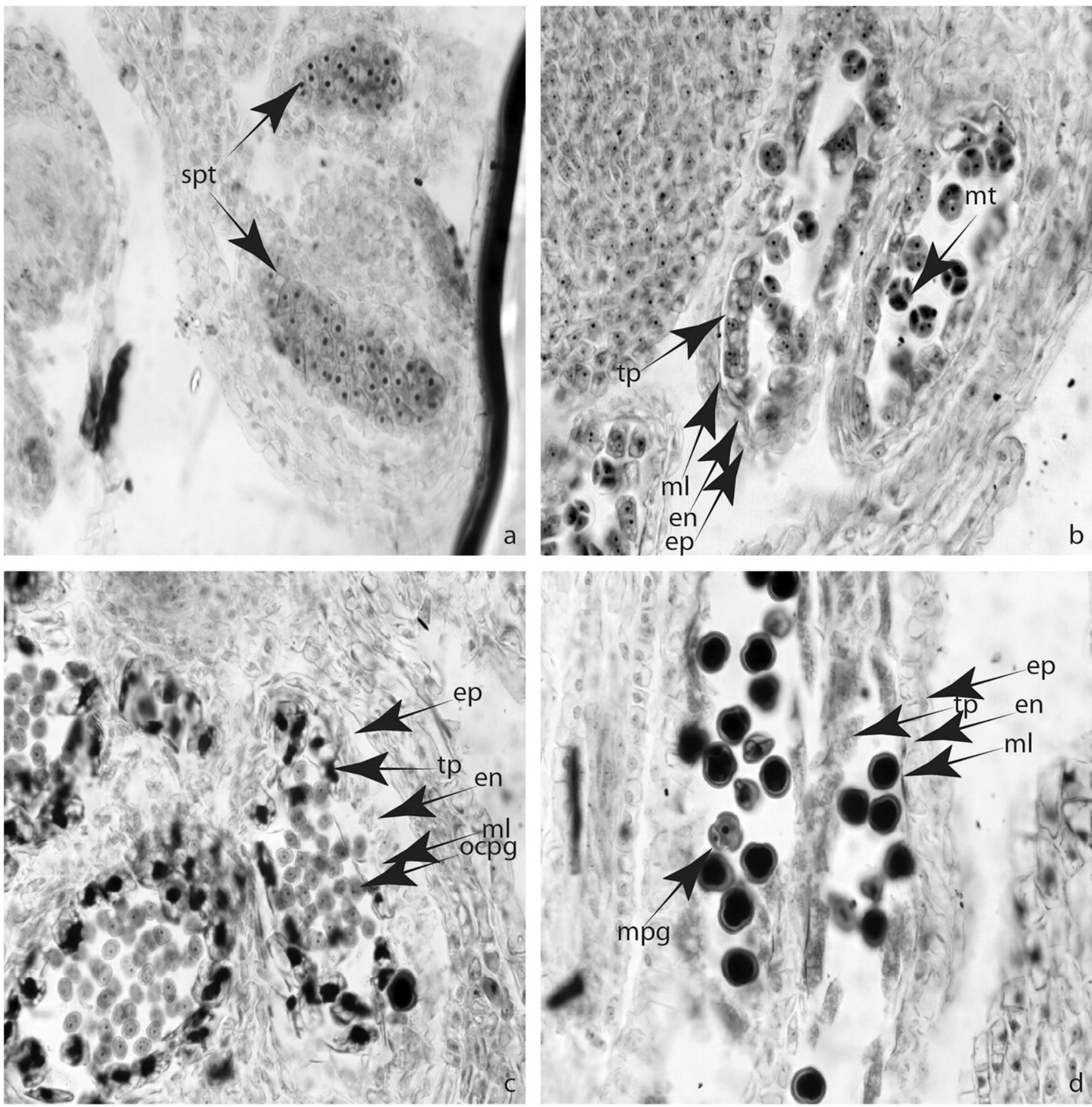

Fig. 1. Anther and development of male gametophyte: (A) sporogenous tissue and anther wall, (B) tetrahedral microspore tetrads and anther wall, (C) one-nucleate pollen and anther wall, and $(\mathbf{D})$ mature pollen grains and anther wall. Magnification $\times 400 . \mathrm{spt}=$ sporogenous tissue; $\mathrm{mt}=\mathrm{microspore}$ tetrad; $\mathrm{ep}=\mathrm{epidermis;} \mathrm{en}$ $=$ endotecium $; \mathrm{ml}=$ middle layer, $\mathrm{t}=$ tapetum; ocpg $=$ one-celled pollen grain; $\mathrm{mpg}=$ mature pollen grain . 
up, separated from each other, and differentiated into MMCs. The meiosis in MMCs passed with insignificant deviations. After simultaneous type of microsporogenesis, predominantly tetrahedral microspore tetrads formed (Fig. 1B). The mature pollen grains, at the time of shedding, were two-celled and morphologically uniform (Fig. 1D). In the Brassicaceae, three-celled mature pollen was previously shown as characteristic for the family (Belyaeva and Rodionova, 1983; Davis 1966; Poddubnaja-Arnoldi, 1982). Up to now, two-celled mature pollen was reported only in Cardamine chenopodifolia (Davis, 1966).

Ovule and development of the female gametophyte. The ovary was bilocular with many ovular primordiums in each locule (Fig. 2A), and only one of these locules underwent further development forming ana-amphitropous bitegmic ovule (Figs. 2B and 3A). The ana-amphitropous ovule was described for genus Lepidim as well by Belyaeva and Rodionova (1983). The gynoecium was stylate, with papillate stigma (Fig. 2C) as described in the characteristics of family Brassicaceae (Watson and Dallwitz, 1992). The well-developed ovule may be defined as medionucellate, sindermal variation, and multilayered subvariation according to the last more detailed classification of the ovule types (Shamrov, 1999); nucellus was represented by two-rowed lateral and multirowed basal area, and the nucellar epidermis. As in most Angiosperms, the innermost layer of the inner integument differentiated into integumentary tapetum (endothelium) that could be observed still on the stage of fournucleate embryo sac (ES) (Fig. 3D). This

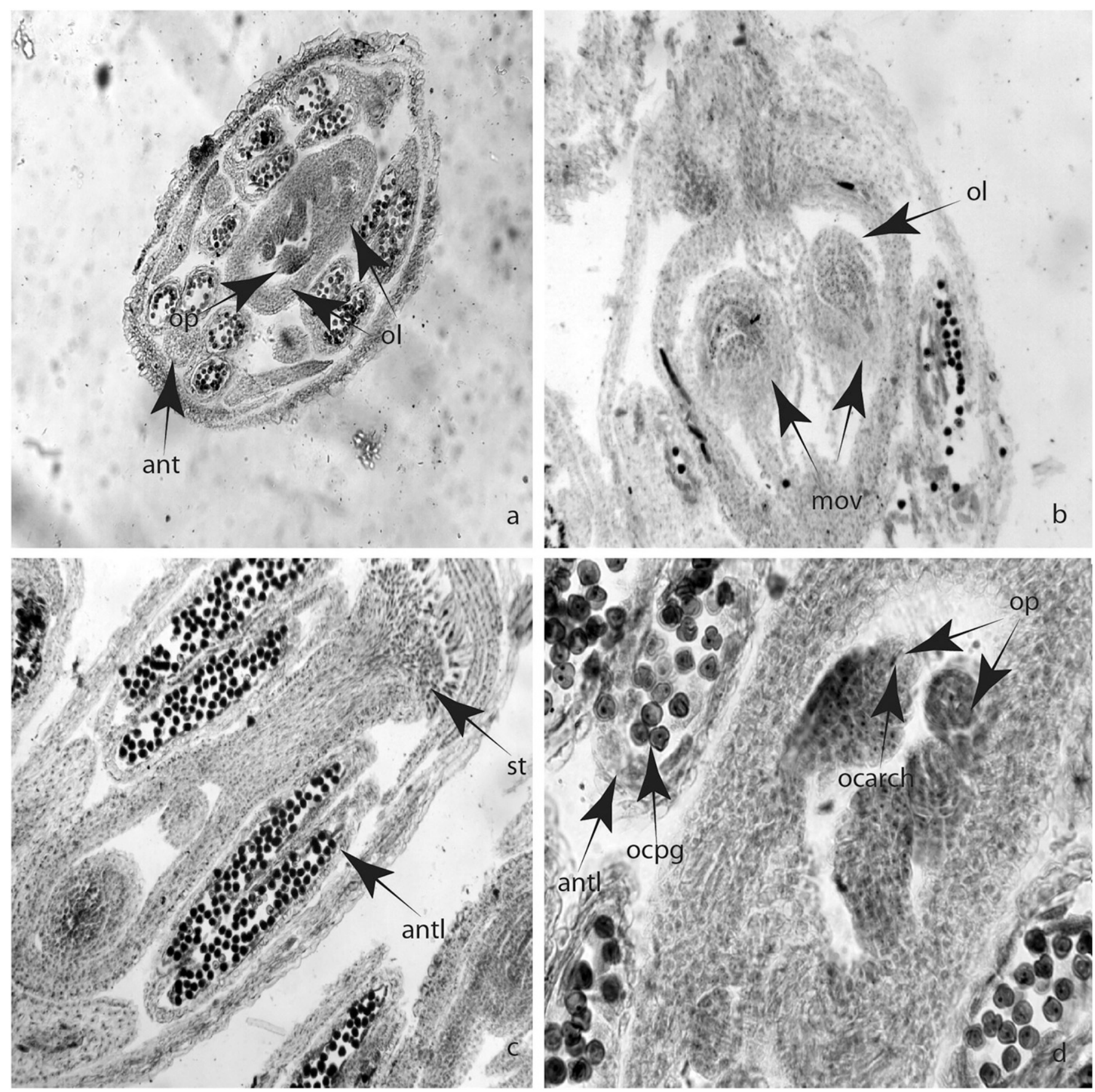

Fig. 2. Flower structure: (A) bilocular ovary and tetrasporangiate anthers, (B) two-locular ovary with ana-amphitropous ovule in each locule, (C) longitudinal section of the flower, and (D) proterandry: one-celled archesporium in the ovule and one-celled pollen grains in the anthers. Magnification $\times 100$ (for $\mathbf{A}-\mathbf{C}$ ) and $400 \times($ for D $)$. ol = ovule locule; ant = anther; mov = mature ovule; ocarch = one-celled archesporium; st = stigma; antl = anther locule; ocpg = one-celled pollen grain. 

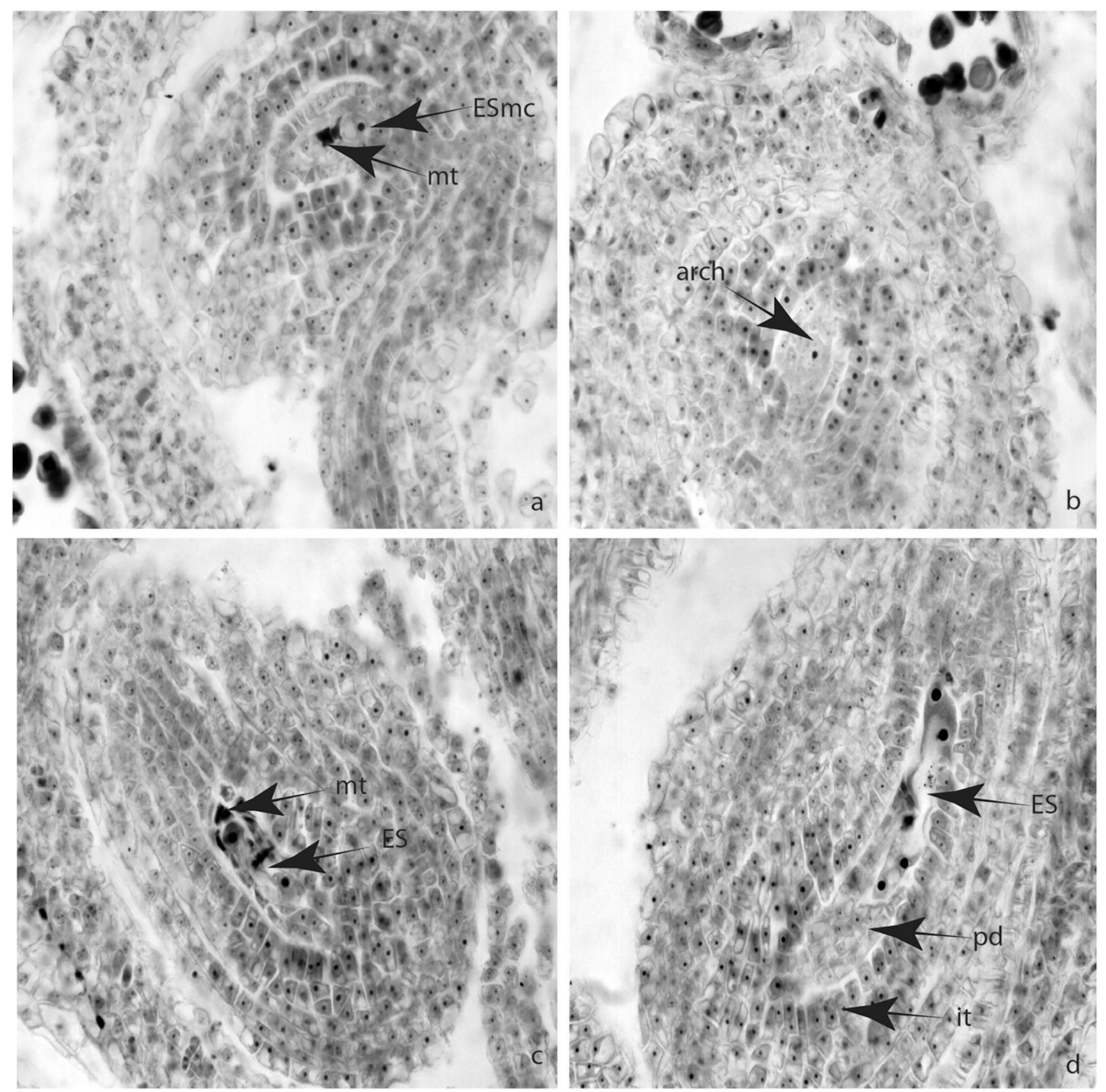

Fig. 3. Ovule and development of the female gametophyte: (A) ana-amphitropous ovule with linear megaspore tetrad in it, (B) one-celled archesporium in the yang ovule, $(\mathbf{C})$ two-celled ES, and $(\mathbf{D})$ four-celled ES. Magnification $\times 400 . \mathrm{ESmc}=$ embryo sac's mother cell; $\mathrm{mt}=$ megaspore tetrad; $\operatorname{arch}=$ archesporium; ES $=$ embryo sac; $\mathrm{pd}=$ podium; it = integumentary tapetum.

finding contradicts the opinion of Shamrov (1999) who reported that in the cited type of ovules, integumentary tapetum did not differentiate.

This study established that the two Lepidium species are strongly proterandrous; when one-celled pollen formed in the anthers, at the same time, archesporium was observed in the ovule (Fig. 2D). Apomixis was not observed.

Within the still young ovule, unicellular archesporium forms hypodermally (Fig. 3B). The formation of unicellular archesporium in the genus Lepidium was reported also by
Belyaeva and Rodionova (1983). The single archesporium cell functions as a megaspore mother cell (MMC) without cutting off parietal cells (Fig. 3A). Later on, the MMC underwent meiosis resulting in the formation of a linear megaspore tetrad. The ES development occurred according to the Polygonum (monosporic)-type. Like in the most representatives of the family Brassicaceae, the functional was the chalazal megaspore of the tetrad (Belyaeva and Rodionova, 1983; Davis, 1966; Watson and Dallwitz, 1992). It passed directly in an embryo sac's mother cell. The other three megaspores degenerated progressively, during the advance of ES development and their remains could be seen until the two-nucleate ES stage (Fig. 3C). The mature ES formed after three successive mitoses consisted of three-celled egg apparatus (usually pear-shaped egg cell and two synergids), central cell (Fig. 4C), and threecelled antipodal apparatus located on a podium in the chalazal part of ES (Fig. 4A). The podium was a cup-like structure representing a tissue composed of nucellus cells disposed below the gametophytic structures of ES. The term podium was introduced by 

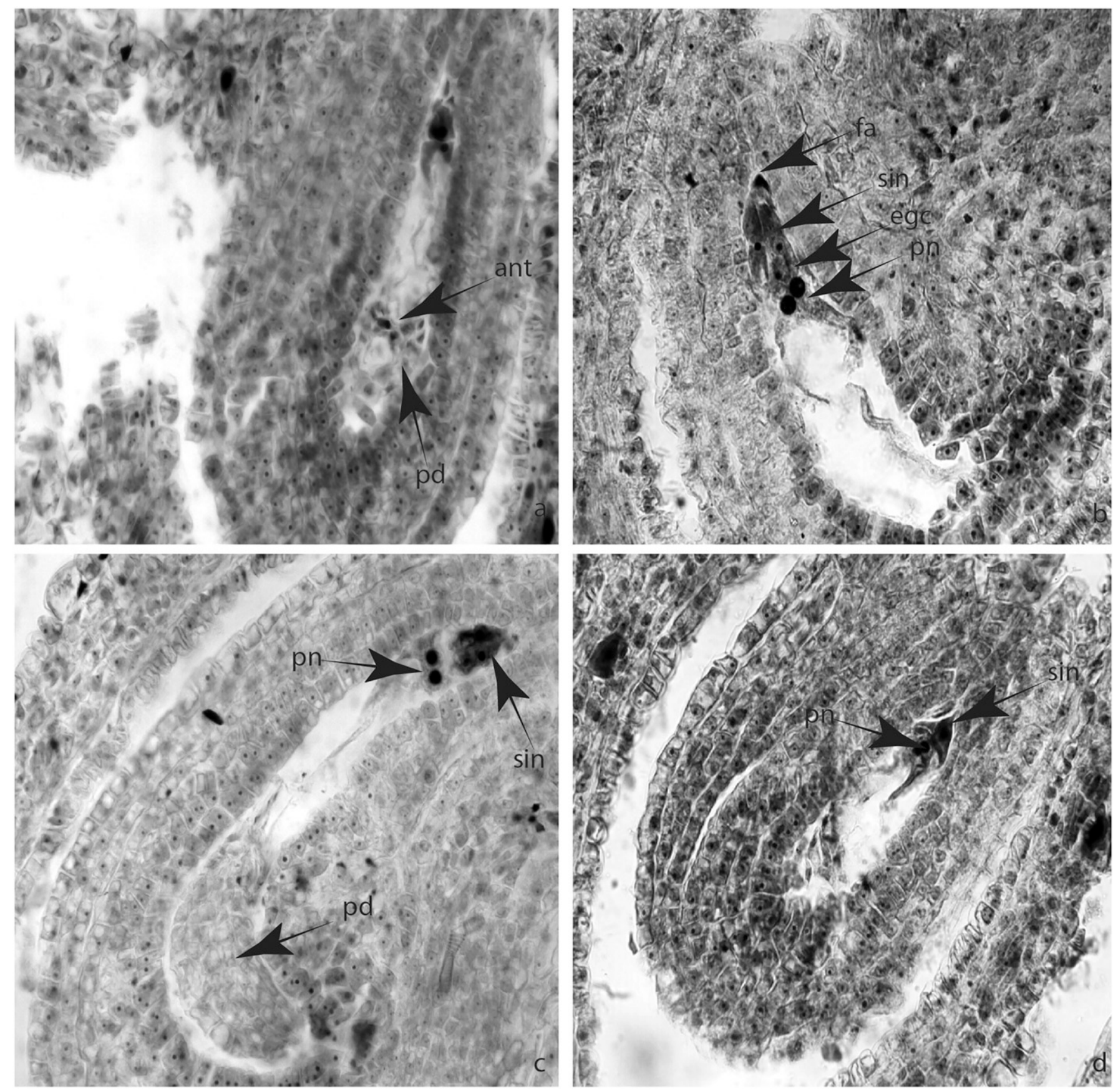

Fig. 4. Ovule and development of the female gametophyte: (A) mature embryo sac (ES) with antipodals and podium, (B) mature ES with egg apparatus and polar nuclei, $(\mathbf{C})$ mature ES with egg apparatus and podium, and (D) mature ES with polar nuclei and hooked sinergids. Magnification $\times 400$. fa $=$ filiform apparatus; $\sin =$ synergid; egc = egg cell; $\mathrm{pn}=$ polar nuclei; $\mathrm{pd}=$ podium.

Dahlgren (1940) to describe the remnant of the nucellus persisting in the chalazal region of ES. Batygina (2002) distinguished two types of podium on the base of the transformation pattern of the cited nucellar zone, namely, columnar and cup-shaped podia. The observed podium in the studied species could be defined as cup-shaped according to the term proposed by Batygina (2002). It differentiated in the early ovule development and could be observed even at the stage of four-nuclear ES (Fig. 3D) and preserved after the fertilization, up to young embryo formation (Fig. 5B). The synergids degenerated after the fertilization. They were hooked (Fig. 4D) as in the most Brassicaceae representatives (Davis, 1966; Poddubnaja-Arnoldi, 1982) and had a filiform apparatus (Fig. 4B) reported as characteristic features for this family (Belyaeva and Rodionova 1983). The antipodals were ephemeral that was shown as typical for the family Brassicaceae (Belyaeva and Rodionova, 1983; Davis 1966; PoddubnajaArnoldi, 1982) and degenerated before the fertilization.

The embryo and endosperm developed after porogamous double fertilization accompanied with a destruction of one of the synergids from the pollen tube penetrating in it through the micropyle of the ovule. The embryogenesis commenced after the endospermogenesis. This assumption allowed us to observe a number of free endosperm nuclei in the ES cavity at the stage of zygote (Fig. 5A). The direction of the cell wall setting in first mitoses in the young embryo (Fig. 5B) indicated that the embryogenesis runs after the Onagradtype shown as a typical type embryogenesis for the family Brassicaceae (Belyaeva and Rodionova, 1983; Davis, 1966; Poddubnaja-Arnoldi, 1982). The globular embryo had a short and massive suspensor (Fig. 5C). In the mature seed, the embryo 

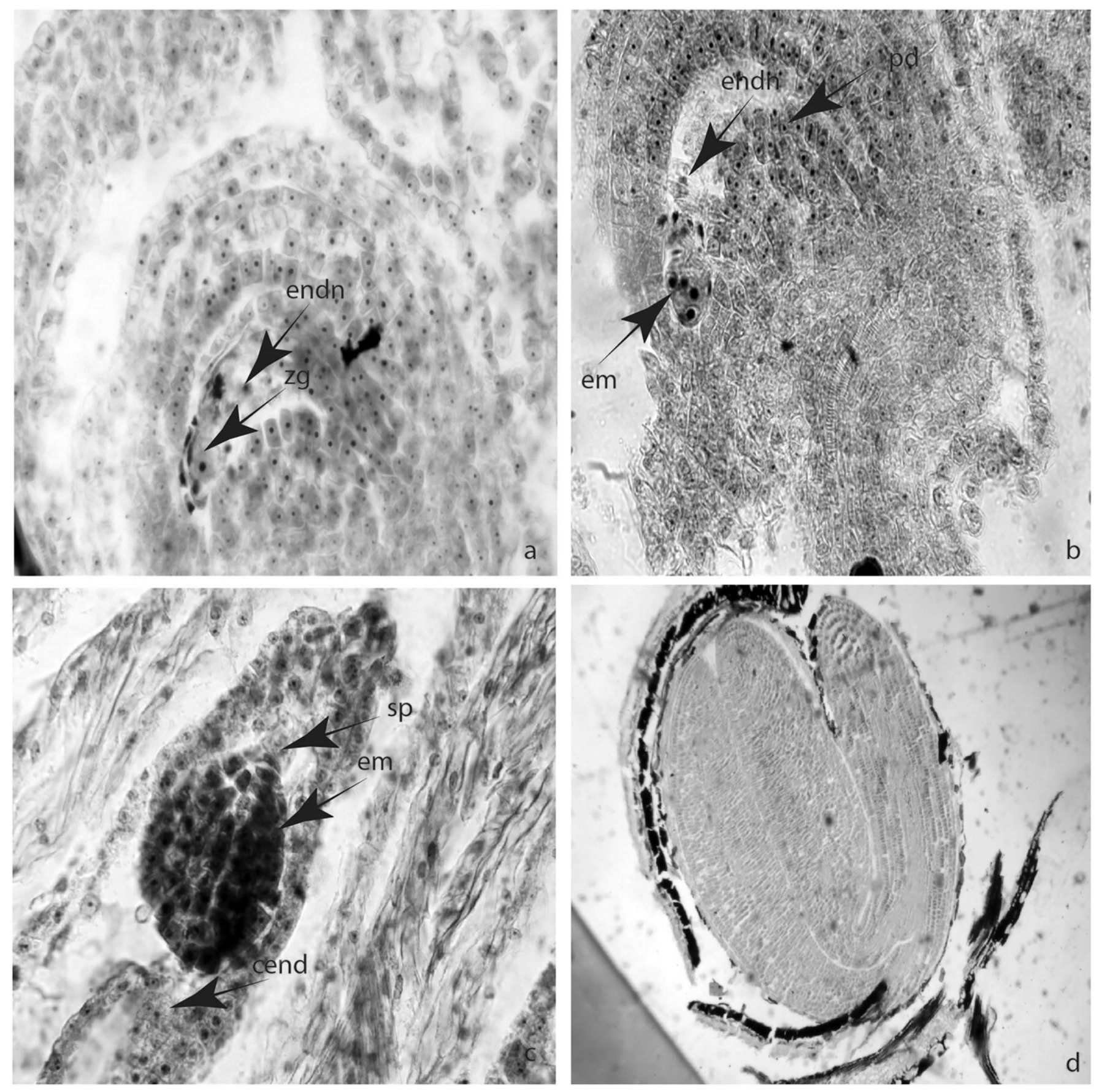

Fig. 5. Embryogenesis: (A) zygote in the ovule, $(\mathbf{B})$ yang embryo and endospermal nuclei, $(\mathbf{C})$ globular embryo, and (D) mature embryo. Magnification $\times 400$. zg $=$ zygote; endn = endospermal nucleus; em = embryo; $\mathrm{pd}=$ podium; $\mathrm{sp}=$ suspensor.

was curved and filled the whole ES cavity (Fig. 5D).

At the beginning of endospermogenesis, the endosperm was nucleate but later on, at the stage of globular embryo, it differentiated into cellular one (Fig. 5C). In the stage of mature embryo, the endosperm was completely consumed. Apomixis was not observed.

\section{Conclusions}

This study described the main features characterizing the embryonal development of $L$. campestre and $L$. ruderale to define the mode of reproduction and reproductive capacity of these species.

The established peculiarities of the reproductive biology characterized the studied species as a sexually reproducing taxa that would guarantee the stability of size of their populations. This is especially important for the conservation of these species as part of biodiversity of the Bulgarian flora given their status of valuable medicinal plants. The data obtained will contribute to the knowledge of the embryological characteristic of genus Lepidium, which currently is fragmented and incomplete. The data may help with the understanding of Lepidium biology and subsequent development of some Lepidium species as new oilseed cash crops for marginal lands.

\section{Literature Cited}

Al-Shehbaz, I. and G.F. Gaskin. 1993. Genus Lepidium L., p. 226-239. In: Flora of North America Editorial Committee (eds.). Vol. 7. Oxford, New York.

Batygina, T.B. 2002. Embryology of flowering plants: Terminology and concepts. Vol. 1: Generative organs of flower. Sci. Publ. Inc. Enfield, NH.

Belyaeva, L.E. and G.B. Rodionova. 1983 Family Brassicaceae, p. 154-164. In: T.B. Batygyna and M.S. Yakovlev (eds.). Comparative embryology of flowering plants. 
Phytolaccaceae-Thymelaeceae, Vol. 3. Nauka, Leningrad, Russia (in Russian).

Chyad, A.H. 2017. Evaluation of anticancer, analgesic and anti-inflammatory activities of the ethanolic extract of Lepidium draba Linn. leaves. Adv. Anim. Vet. Sci. 5(1):7-13.

Dahlgren, K.V.O. 1940. Postamentbildungen in den Embryosäcken der Angiospermen. Bot. Notiser 4:347-369.

Davis, G. 1966. Systematic embryology of the angiosperms. Wiley, New York, NY.

Delipavlov, D., I. Cheshmedjiev, M. Popova, D. Terziiski, and I. Kovatchev. 2003. Identifier of plants in Bulgaria, pp. 137. Plovdiv Akad. Publ. Agricultural University, Plovdiv, Bulgaria.

Eriksson, D. and A. Merker. 2011. Cloning and functional characterization of genes involved in fatty acid biosynthesis in the novel oilseed crop Lepidium campestre L. Plant Breeding 130:407-409.
Gan, J., Y. Feng, Z. He, X. Li, and H. Zhang. 2017. Correlations between antioxidant activity and alkaloids and phenols of maca (Lepidium meyenii). J. Food Qual. 2017:1-10.

Ivarson, E. 2016. Development of Lepidium campestre into a new oil and catch crop. Swedish Univ. Agr. Sci., PhD Thesis.

Ivarson, E., N. Leiva-Eriksson, A. Ahlman, S. Kanagarajan, L. Bülow, and L.H. Zhu. 2017. Effects of overexpression of WRI1 and hemoglobin genes on the seed oil content of Lepidium campestre. Front. Plant Sci.

Kamani, M., E.S. Hosseini, H.H. Kashani, M.A. Atlasi, and H. Nikzad. 2017. Protective effect of Lepidium sativum seed extract on histopathology and morphology of epididymis in diabetic rat model. Intl. J. Morphol. 35(2):603-610.

Merker, A., D. Eriksson, and N.O. Bertholdsson. 2010. Barley yield increases with undersown Lepidium campestre. Acta Agr. Scand. B Soil Plant Sci. 60(3):269-273.
Poddubnaja-Arnoldi, V.A. 1982. Characteristics of the Angiosperms families on cytoembryological features. Nauka, Moskva, Russia.

Romeis, B. 1948. Mikroskopische technik. Leibniz Verlag, Munich, Germany.

Sánchez, J.M.L., Z.A. Serrano, J.A. Durán, H.S.G. Morales, and P.B.M. Álvarez. 2017. Peruvian maca and possible impact on fertility. J. Nutr. Health Food Eng. 6(5):00217.

Shamrov, I. 1999. The ovule as the base of the seed reproduction in flowering plants: Classification of the structures. Bot. J. 84(10):1-35.

Sundara, R.S. 2000. Practical manual of plant anatomy and embryology. Anmol Publ. Pvt. Ltd., New Delhi, India.

Watson, L. and M.J. Dallwitz. 1992. Cruciferae Juss. In: The families of flowering plants: Descriptions, illustrations, identification and information retrieval. Version: 20 May 2010. $<$ http://delta-intkey.com>. 